\title{
Team Equilibrium and Innovation Performance
}

\author{
Marco Vinicio Ferruzca Navarro \\ Universidad Autónoma Metropolitana \\ Mexico City, MÉXICO \\ mvfn@correo.azc.uam.mx; \\ Jorge Rodríguez Martínez \\ Universidad Autónoma Metropolitana \\ México City, MÉXICO \\ rmj@correo.azc.uam.mx
}

\author{
Josep $\mathbf{M}^{\mathrm{a}}$ Monguet Fierro \\ Universitat Politècnica de Catalunya Metropolitana, \\ Barcelona, SPAIN \\ jm.monguet@gmail.com \\ Alejandro Trejo Omeñaca \\ Onsanity Solution S.L. \\ Barcelona, SPAIN \\ alextrejo@onsanity.com
}

\begin{abstract}
Today competition has increased between organizations and they are urged to improve constantly their performance throughout innovation if they want to survive and be profitable. However, an organization can't be innovative if it doesn't counts with creative people and build teams to strength its creative and innovative capabilities. Besides, the impact of technology in innovation has been widely studied but there are others major aspects that need more exploration to understand their influence in it. For example, collaborative work, multicultural teamwork, creative teamwork, entrepreneurial behavior, etc. Some authors suggest more research is needed regarding organization capabilities that promote effective relationships for innovation. According to West (2002), three issues dominated research about creativity and innovation among teams: the characteristics of group tasks and their impact in the creative-innovative process; the role of diversity in knowledge and skills between team members; and team integration. If these issues are relevant for team creativity and innovation, then frameworks and tools to configure teams are necessary. It may be taken by granted that there must be an equilibrium of roles within teams to foster creativity focused on innovation. So, in this paper several approaches of creativity are reviewed. Then a conceptual model to foster Team Equilibrium and strength innovation performance is proposed and applied through a webbased tool. A first empiric exploration is presented. The proposed model can be used as a basis to develop tools that helps teams for self-analysis.
\end{abstract}

Keywords - Innovation, Creativity, Team Performance. Design

\section{INTRODUCTION}

Several authors argue that nowadays organizations face turbulence and uncertainty because of fast changes in economy, technology and society (Mascia et al. 2012). Besides quality, organizations have to pay attention to others factors for attracting consumer attention to their products and services. That's why firms have to increase their performance through innovation in the wider sense of the concept. They need to strenght their creative and innovative capabilities.

Junarsin (2009) indicates creativity is central to competitiveness and some how it is linked with the organization strategy where material, technological and human resources are important but on the basis of creativity. The professional community in companies also considered creativity as one of the key factors for leadership (The IBM Global CEO Study 2010, IBM Institute for Business Value)

The impact of technology in innovation has been widely studied but there are others major aspects that need more exploration to understand their influence in it. For example, collaborative networks, multicultural teamworks, network structures, creative teamworks, enterprenurial behaviour, etc. Mascia et al. (2012) suggest more research is needed regarding organization capabilities that promote effective relationships for innovation.

According to West (2002), three issues dominated research about creativity and innovation among teams: the characteristics of group tasks and their impact in the creativeinnovative process; the role of diversity in knowledge and skills between team members; and team integration. If these issues are relevant for team creativity and innovation, then tools to configure work teams are necessary. It may be taken by granted that there must be an equilibrium of roles within teams to foster creativity focused on innovation. So, in this research, a conceptual model to define an integral profile of the team has been set up, and applied. This framework proposes a webbased tool that a team can apply for self-analysis, and that take into account psychological, entrepreneurial, organizational, learning and design behavior.

\section{CREATIVE TEAMS TO FOSTER INNOVATION}

In this paper we assume that creativity and innovations are commonly associated with the generation of new ideas, products, services or processes (Seidel et al. 2010). While creativity is more oriented to the development of novel ideas, innovation is more focused on their application.

Even when in an organization there are creative persons, it doesn't guarantee innovative teams. As Trompenaars et al. (2010) underline, it is a necessary condition but not enough by itself.

Research on creativity has probed that individuals have different styles and creative capabilities. Using this diversity among individuals for creating groups is crucial for the team to work efficiently and effectively. A heterogeneous team, regarding styles, will perform better than homogeneous teams. 
For organizations this creative diversity can be useful for adaptation and innovation. Individuals can work better if they share their knowledge and skills with other ones with different styles and creative capabilities instead of the opposite circumstance. If there is an open atmosphere where trust is incrusted, then individuals will bring their creativity to transform it in innovations. However, team leaders sometimes they don't realize the importance of diversity. Mannix and Lean (2005) proposed several levers to shape, influence, and align team processes: team design, training and development, and lidership. And they recommended that research on these levers should be developed and applied.

Regarding team design, they recommend to focus research to refine task and system-design interventions. Besides, they suggest that research about team composition is still needed.

Work teams are an important component of organizations and thus to study and understand how to improve work team innovation is of utmost importance. Even when past research works have demonstrated that independent individuals can be more creative than those working in teams, he suggests teams are more innovative. Then organizations need to be concerned also about developing creative and innovative teams (PirolaMerlo et al., 2003).

Organizations should be capable to manage the collective talent instead of the individual one, through teamwork and joint effort (Akehurst et al. 2009). Favorable context for collaboration are required, so individuals can be more creative and teams more innovatives.

Organizations might benefit from creating tools that allow assessing team behavior regarding different aspects, which are relevant for innovation. These tools can also incentive cooperation, collaboration, and shape collective intelligence at different levels: teams, firm and the organization.

Teamwork is supposed to lead to creativity and innovation because of diversity and knowledge among the members of a team. However, teams can experience many problems related to technical, legal, structural and social dimensions (Pallot 2009).

Researchers from other domains, particularly sociology, have focused on more macro issues concerning the influence of the environment on creativity (Ford, 1996). The macro perspective has also been associated with an interest in innovation, 'the intentional introduction and application of ideas, processes, products or procedures, new to the relevant unit of adoption, designed to significantly benefit' (West \& Farr, 1990). Because innovation involves newness and usefulness (benefit), it can be seen to incorporate creativity, in addition to adoption/implementation (Ford, 1996). These definitions explain how researchers define and differentiate creativity and innovation. However, we acknowledge that popular use of the terms creativity and innovation does not necessarily adhere to these definitions.

III. THEORETHICAL AND PRACTICAL APPROACHES TO FOSTER CREATIVITY AND INNOVATION IN TEAMS
Different approaches have been developed to foster creativity. In this paper we review briefly some, which are, intertwined to innovation, but in specific those that can be useful to develop a modelo to foster Team Equilibrium. We don't discuss deeply the psychological aspects of individuals since our research work is not trying to discover the personality of a team member while using a magical tool. It is focused in inspiring teams and helps them to understand and improve their profile as a team in an effective manner through socialization and collaboration. Thus, to foster awareness of collective intelligence in multidisciplinary teams may benefit from existing theoretical and practica approaches.

In this context, the theorethical and practical approaches reviewed represent also a pedagogy effort to understand better the creative process with the aim to encourage design-driven innovation applied to innovative projects. In this context, Team Equilibrium can contribute to achieve this goal.

The approaches reviewed are: Kolb’s learning styles, Myers Briggs model of personality, Belbin team roles, the 10 faces of innovation and the six thinking hats of de Bono.

\section{A. Kolb's learning styles}

Kolb developed an experiential learning theory from which he generate his learning style inventory. His theory works in two levels. The first one implies a four-stage cycle of learning and four different learning styles.

According to Kolb effective learning should be considered only when a person accomplish four stages: having an experience, reflecting on it, building abstracts concepts and trying out what the person has learnt. On this basis, Kolb explains that people naturally prefer a certain different learning style. The learning style chosen depends on how a person approaches to a task (Processing continuum) and the emotional behaviour of the person (perception continuum). For Kolb there are different learning styles: Diverging (Based on feel \& watch); Converging (base don (think \& do); Assimilating (base don thinking \& watch) and finally, accommodating (base don feel and do).

\section{B. Myers-Briggs Type Indicator (MBTI)}

The MBTI is a tool to measure personality traits through a psychometric questionnaire. Even when it was developed by Katharine C. Briggs and Isabel Briggs Myers, it is based on the theorethical work of Carl Gustav Jung.

This instrument allows capturing how people perceive the world and making decisions. For Jung, if we discover how we process information, then we will be able to understand better how we do it and why we feel what we feel. As a consequence two psychological processes can be distinguished: perception (the act of receiving information) and judgement (the act of processing information). Information can be perceived in a sensorial or intuitive way and it is judged in a rational or emotional way. These four mental processes operate for the external world of persons and things, but also for the internal world linked to subjective experience. The MBTI propose a set of 16 types of personalities (Trompennars et al., 2009). 


\section{Belbin Team Roles}

For Belbin a team is not a group of people with different job titles. A team represents a group of individuals, where each one of them has a role that should be understood by other members. A person has its own behaviour and its own tendency to participate, collaborate, and interact with others. Whitin a team is very important to recognize the strengths and weakness of each member with the intention to perform as good as possible. Belbin suggests nine team roles.

To identify the role of a person can be useful to: build effective working relationships; improve performance of teams; increase self-awareness and effectiveness in a personal level; build mutual trust and common understanding; etc.

\section{The 10 faces of innovation}

Within the design field, Kelly and Limman (2006) propose a human-driven innovation strategy. Individuals and teams foster innovation in the organizations. They propose a set of ten innovative personages that must be part of innovative teams. Each of them has a role to perform. For them innovation emerge when persons creates value through the implementation of new ideas.

\section{E. Six Thinking Hats}

It is a method to support discussions and take decisions within work groups. A set of six thinking hats is proposed with aim to face a situation and solve a problem (de Bono, 1985). Each hat should be applied during the solving problem process because it represent a different way to think and thus can be considered as a thinking direction.

\section{SYNTHESIS OF LITERATURE REVIEW AND RELEVANCE TO THIS WORK}

From each of the works reviewed some ideas can be discussed and used in an integrative way to foster Team Equilibrium during the development of innovative projects, which involve design and are intensive in creativity.

In relation to Kolb's learning styles, we can infer that learning is a particular part of our way of being, linked to our personality, and it is especially relevant for the purpose of creativity, design and innovation. Learning implies living experiences and each person has a different ways to approach it. To achieve learning it is necessary to complete a cycle.

Since we take as granted that there are different learning styles then it is necessary that an organization recognizes and support all of them because learning has a strong relationship with creativity.

Learning is in fact a fundamental step on the processes of design and innovation, as in teamworking people suggest ideas while learning from their colleagues and counterparts.

Learning is after all a communication process where efficiency depends upon the adequacy of the messages and the communication strategy being followed. If a member of a team is conscious about how each other member learn, then he will try to communicate more precisely, using an appropropiated strategy. For instance if someone need self-experiment for learning, it will not be very useful to describe conceptually the ideas to him.

Regarding the MBTI, different treats of personality influence in the way we behave in general, and how each one of us particularly performs under determined circumstances and interact with other people. During the design and development of a project of innovation, that involves amounts of creativity, several individuals participate and are subject to pression. They have a particular behaviour and specific assignments to succed.

Because individuals form a team, and if it were possible to speak about the "personality of a team", then team personality will be a combination of the personalities of its members. Obviously is not as simple as a sum, but it may be probably something similar to a polynomial addition of the member's personalities where the terms of the polynomial, meaning the weighting of each member, varies in time according to environment, interactions between people and many other aspects.

The proposal of Belbin is more focused in improving team performance within an organization. The role that defines a person is based on its strengths and weakness.

To our conceptual model of Team Equilibrium a framework that proposes the positions is absolutely necessary, like if it was a football team. Finally the objective of the team is to create design and innovate, making new products and services in a company.

The positions within a team can be partially dependent on the personality or the style of learning of each member, and ideally the best option is to cover each position with the most appropriated candidate.

The team roles proposed by Belbin can work well for any kind of team, a scientific expedition or a board of directors in a company. However, the ten faces of innovation suggested by Kelly and Limman are particularly relevant for design and innovation and for teams were creativity is especially relevant.

The proposed faces of innovation don't represent a team, but the skills and attitudes that define the different steps of creativity. As Team Equilibrium is devoted to creativity, design and innovation projects, this approach is very useful as a list of innovation fundamentals oriented to the realization of innovative projects.

\section{TOWARD A CONCEPTUAL MODEL OF TEAM EQUILIBRIUM}

\section{A. Integrating the reviewed approaches to a conceptual model for team equilibrium}

The theoretical approaches reviewed revealed useful information to understand better creativity and to foster Team Equilibrium in projects of innovation, which involve design knowledge. Some considerations are explained forward.

A conceptual model of Team Equilibrium can use the Kolb approach as a strategy to define the personality of each team member.

The participants' knowledge about their own learning style as part of their personality may have important benefits in 
different ways. If a person knows his strenghts and weakness for learning, it will be easier to understand or connect with something that is being discussed or worked during the process of creation, design or innovation. In the same way if one knows how other people learn, then one may try to expose their ideas in a more effective way.

According to the MBTI, there are not good or bad personalities; there are different styles of responding to the conditions in life and in relation with others. Good teams work well because they are equilibrated in terms of heterogeneity of people and they know one each other and adjust the behavior of the team promoting in each moment the most appropriated person for the job to be done. To know why and how the people feel motivated, to predict how someone will respond to a challenge can be relevant during the development of a project and the discussion of ideas and design approaches.

For a conceptual model of Team Equilibrium, the personality of an individual can be used to attempt to define the profile of a team. It can consider how the MBTI criteria for each one of the members of the team leverage over the team behavior and performance

Organization should consider the weakness and strengths of a person before integrating it in a team. There should be a balance of different persons when integrating a team.

From Belbin's work, it's clear that the profile of a team has to cover the necessary positions. Depending upon the type of project or the kind of skills and capabilities that are needed in each moment, certain positions are more o less critical.

The ten faces proposed by Kelly and Limman can be used as a complement of Belbin team roles whit the specific capabilities, attitudes and skills that creative projects demand. .

Finally, the six thinking hats of Bono can serve as an interface to present a visual synthesis of the final team profile in a comprehensive and simple manner. The strong and weak aspects of a team are clearly visualized through the representation of a hexagon formed by the six thinking hats. The image offers a very quick vision of the team profile.

\section{B. The conceptual model of Team Equilibrium}

As a synthesis of the theoretical and practical framework studied in this research, a new model called Team Equilibrium is proposed. This new model wants to be a contribution to define the characteristics of a group of people considered as a team that is going to perform a project of innovation.

According with the literature, an assumption is done, considering that teams that present equilibrium will obtain better performance and outputs tan those that are not equilibrated. In this model equilibrium means symmetry and balance of all professional characters.

A resume of the model is sketched in Fig. 1, there are three packs of characteristics that must be measured in order to determine an individual professional character inside a team. See table 1.

\begin{tabular}{|c|c|}
\hline $\begin{array}{c}\text { Personal } \\
\text { Characteristics }\end{array}$ & Description \\
\hline $\begin{array}{l}\text { Professional } \\
\text { Personality }\end{array}$ & $\begin{array}{l}\text { The professional personality of an } \\
\text { individual may be determined using a } \\
\text { combination of the learning styles and } \\
\text { the personality types. } \\
\text { Basic tendencies of individuals will } \\
\text { leverage their contribution and } \\
\text { performance depending on the role } \\
\text { they develop inside the team. }\end{array}$ \\
\hline $\begin{array}{l}\text { Professional } \\
\text { Behaviour }\end{array}$ & $\begin{array}{l}\text { The professional behaviour may be } \\
\text { defined considering the group of } \\
\text { professional general roles and the more } \\
\text { specific innovation roles. } \\
\text { People have preferences and a natural } \\
\text { tendency to consider them prepared or } \\
\text { better performers in specific roles and } \\
\text { as well as worst on others. This } \\
\text { believes configure a professional } \\
\text { behaviour that reinforces the role of the } \\
\text { individual. }\end{array}$ \\
\hline $\begin{array}{l}\text { Professional } \\
\text { Experience }\end{array}$ & $\begin{array}{l}\text { And professional experience is a last, } \\
\text { but not least, condition that defines the } \\
\text { individual professional character. This } \\
\text { element may be important for people } \\
\text { with years of professional experience. }\end{array}$ \\
\hline
\end{tabular}

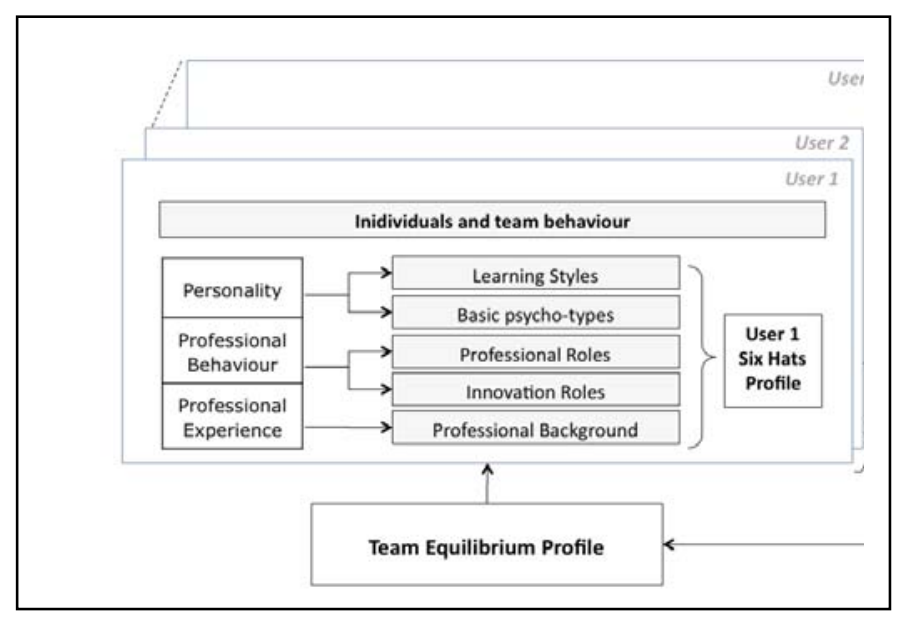

Fig. 1. Conceptual model for team equilibrium

With those three groups of characters, individuals may be described and classified in a unique way, and so teams formed by these individuals may also be analysed, and assessed in terms of equilibrium.

The meaning of equilibrium in people and in teams is quite different. Individuals are generally bias, and the concept of equilibrium is related with the self-knowledge and attitude of each one that allows accurate and fine behave, while for teams, 
equilibrium exists if they are formed by people that balance and complement one each other.

\section{AN ATTEMPT TO APPLY THE CONCEPTUAL MODEL THROUGH A WEB-BASED TOOL}

\section{A. Design of a the web-based tool}

The Team Equilibrium application, inspired and founded in the theoretical background described above, has to be considered a tool to help people analyse the heterogeneity and completeness of the teams they may form with the intention of working in innovation projects were creativity and design are relevant skills.

The intention of the Team Equilibrium application is not to determine the personality of each individual member of the team, but to add in a meaningful way the characteristics of all the people in a team, considering that everybody has been measured with the same criteria and dimensions.

The output that the application delivers to teams is based in the broadly recognized Six Thinking Hat model that summarizes in 6 colours the fundamental dimensions representing the positions that may adopt someone to get success during any kind of work or task:

- Black for judgement and devil's advocate

- $\quad$ Red for feelings and intuition

- $\quad$ Blue for managing and control mechanisms

- Green for creativity and production of ideas

- Yellow for brightness and optimism

- White for facts and information

In the Team Equlibrium model the transposition of the personal hexagons of the members of the team is considered the profile of the team.

When users have acceded to the application (Fig. 2), are asked to select their personal options (Table 2) in three questionnaires (Fig. 3).

The personality and professional profile choices offered to the user combine through a polynomial algorism the union of all the options proposed by Kolb, Myer-Briggs, Belbin and Kelly-Limman frameworks.

Once the user has selected their options in the list can see immediately an irregular hexagon representing his /her profile based upon the tendency in each one of the Six Hats of de Bono model. (Fig. 3)

TABLE II.

\section{CHARACTERISTICS OF A PERSON}

\begin{tabular}{|l|l|}
\hline Personality & $\begin{array}{l}\text { Users are asked to select one cell of each pair of } \\
\text { dichotomies that best define their personality. }\end{array}$ \\
\hline $\begin{array}{l}\text { Professional } \\
\text { Profile }\end{array}$ & $\begin{array}{l}\text { Uses are asked to select two of the following roles } \\
\text { that best define their professional behavior }\end{array}$ \\
\hline $\begin{array}{l}\text { Proffesional } \\
\text { experience }\end{array}$ & $\begin{array}{l}\text { Users are asked to select just one of the following } \\
\text { areas that best define their professional experience. }\end{array}$ \\
\hline
\end{tabular}

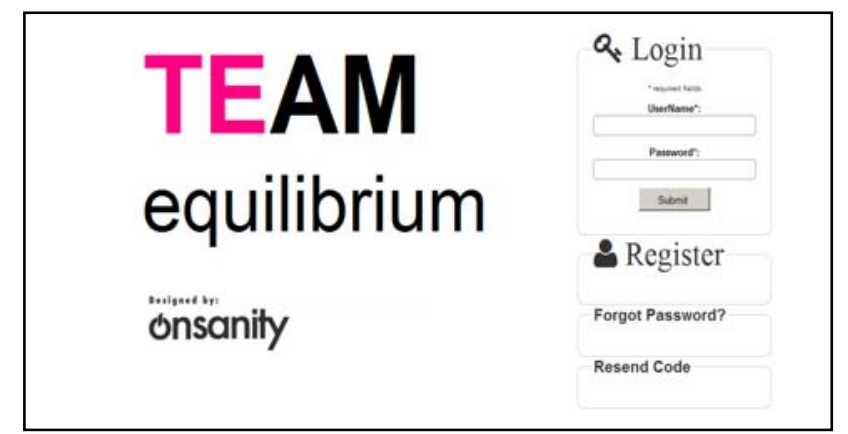

Fig. 2. Access to Team Equilibrium Application

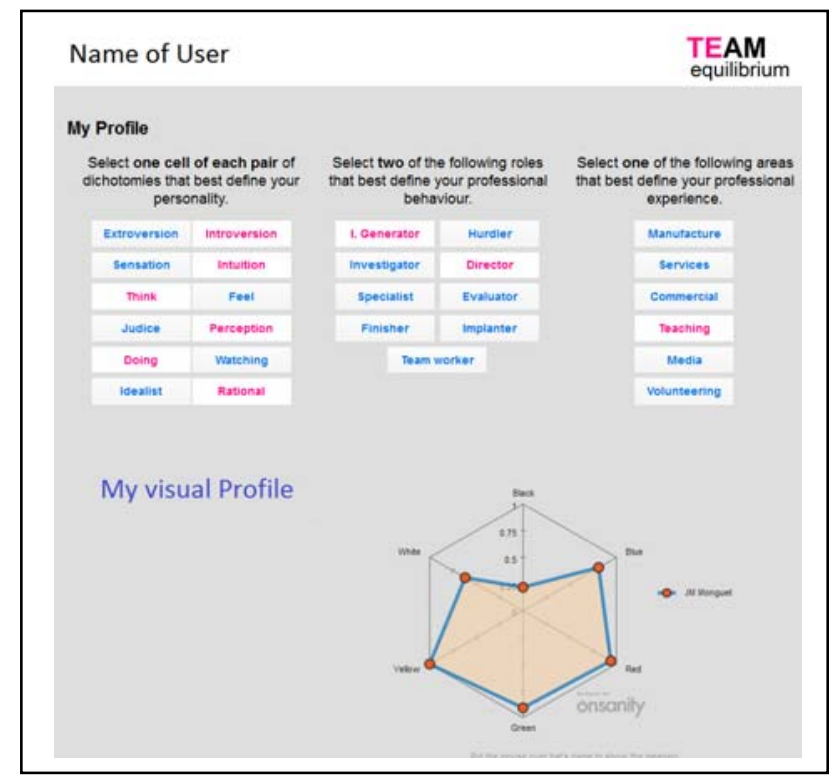

Fig. 3. The user selects the options that best define his personal profile, in each one of the questionnaires.

The options of the questionnaires are permanently open to the users, allowing them playing and changing some of the answers if they don't agree with the form of their hexagon.

A user may create as many groups as he or she wants, inviting other people to join or being invited by others. Once admitted in a team, any member of the group is able to see the profile of the group (Fig. 4).

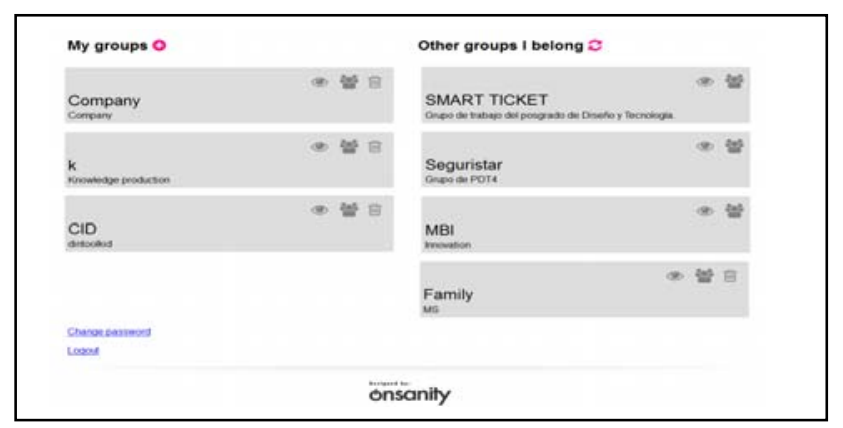

Fig. 4. User may create as many groups as they want, invite people and be invited by other user to their groups 
If a new member is invited to the group everybody may see how this person matches with the group, complementing a weakness or reinforcing an aspect already strong (Fig. 5).

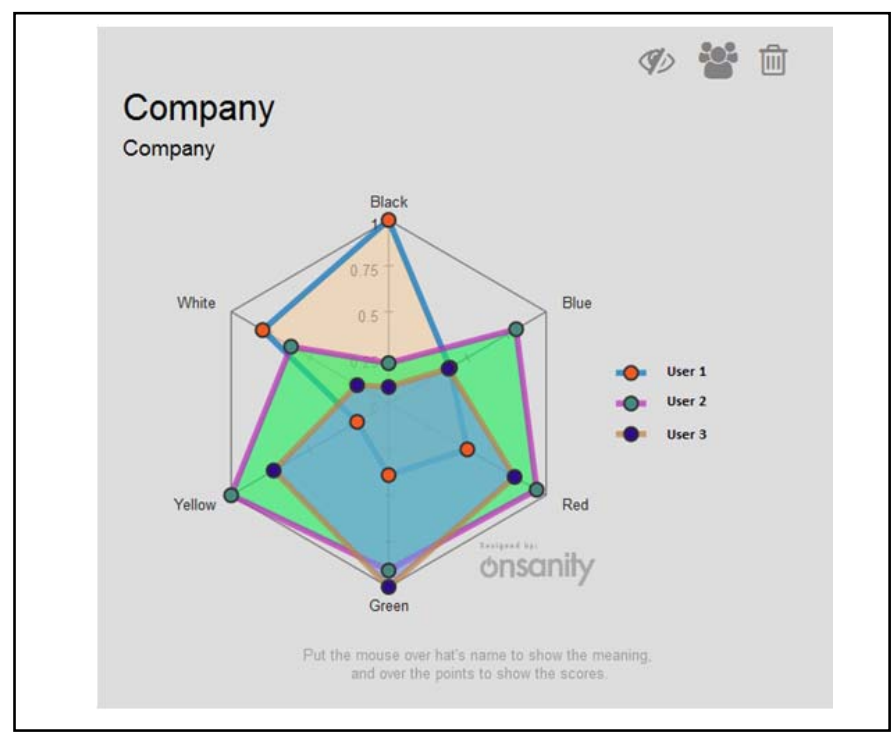

Fig. 5. Members of the group are able to see their profile as a semitransparent superposition of the hexagons of all the integrants.

Fig. 6 allows the comparison of two teams that share the user number 1 . Although team Company 1 has only three people, they cover as well as team Company 2, the whole hexagon. A discussion here is that depending on the kind of work to be done and decisions to be taken, team Company 1 may present advantages over team Company 2.

As said before, the intention of Team Equilibrium is not to determine personal profiles, not a normalized group profile, something on the other hand difficult to assess, but to provide the team with a tool to know and eventually discuss the characteristics of the team regarding the process and progression of work during a project of innovation.

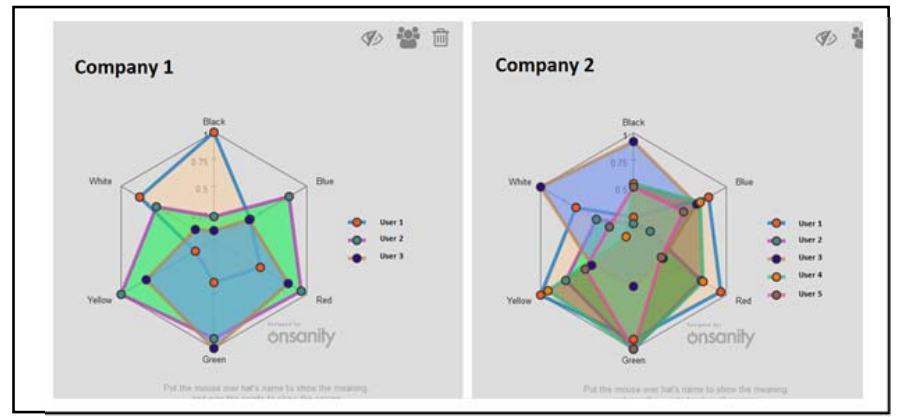

Fig. 6. The profiles of groups may be easily discused and/or compared.

\section{B. Application of the web-based tool}

1) The first exploration and results
To test and assess the validity and adequacy of the Team Equilibrium tool for the purpose defined, the work has been done in two phases, the first one was conducted without any kind of digital tool, working with groups of master students involved in the development of projects that extend over a year. The second phase was based in the use of a digital tool that facilitated to users the Team Equlibrium model application. The first phase allowed, thanks to different tests and experimentation done with the groups, the design of the tool that was used in the second phase.

The test and assessment process described in this paper represents a first step in the research, and is devoted to see the usability of the tool and the self identification of users with the outputs, both in relation to themselves and in relation with other members of the team that they also knew through personal relationship.

The method of research for this first phase of the test has been based on a focus group inspired method, with 60 people that have used the application. Grade and undergraduate students from design and engineering schools composed this first group of users. The groups were composed of 3, 4, 5 or 6 members. See Table III.

The users were proposed to go to the application http://team.onsanity.com and do the whole job by themselves without any kind of instruction or advice. In all the cases, students had first a class in which the theoretical background described in this paper was lectured and discussed in a didactical way.

In the same or in the next class, students were asked to give their opinion about the tool and outputs. The opinions were collected applying a focus group approach, through an open discussion during classes. The professor facilitating the debates of the focus group was always the same and used the same guide for questions.

TABLE III. SET OF GROUPS FOR TESTING THE TEAM EQUILIBRIUM APPLICATION

\begin{tabular}{|r|r|r|}
\hline People & $\begin{array}{r}\text { Number of } \\
\text { groups }\end{array}$ & Group of \\
\hline 21 & 7 & 3 people \\
\hline 12 & 3 & 4 people \\
\hline 15 & 3 & 5 people \\
\hline 12 & 2 & 6 people \\
\hline Total people & Total groups & \\
60 & 15 & \\
\hline
\end{tabular}

At the end of the debates three main questions were asked regarding:

- $\quad$ The level of identification with personal description, the personal one and from my classmates.

- The usability of application (clear, intuitive and easy to use). 
- $\quad$ To know if the profile of the team may result useful for the dynamics of the team.

In all cases, the final consensus about Team Equilibrium was more or less the same and may be summarized as follows:

In general terms everybody felt quite comfortable with his or her hexagonal profile. The Fig. 7 presents the hexagon of the 60 people comparing the total score per hat, putting in evidence the natural creative bias of the group

Few people found difficulties in the use of the application, and if so it was due to the fact that they were using not updated smart phones.

Everybody agreed about the intuition of the utility of the profile although because of the novelty nobody knew exactly how and when to use the team profile.

There were no relevant differences between the opinions of grade and master students except in the last question that in the case of master students they contributed significantly with ideas to improve the tool in order to be more useful for the management of the team during the execution of the project. We consider this contribution a form of expressing their support to the Team Equilibrium tool.

Next steps of experimentation and assessment of the model and tool Team Equilibrium will extend the base of users with professionals, and with other groups of students in the management, science and humanities fields to check the accuracy of the measure algorism, and will look at the influence of Team Equilibrium in the performance of the different teams developing their projects.

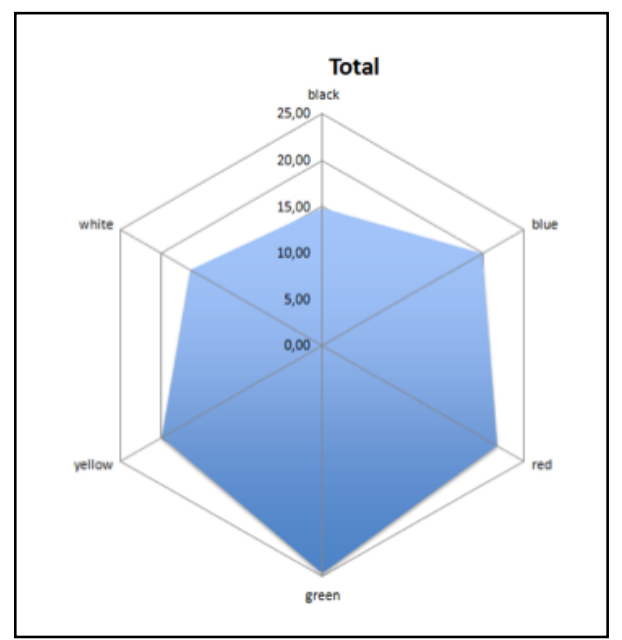

Fig. 7. Hexagon of all 60 participants in the first experimental phase.

\section{CONCLUSIONS}

The objective of the work presented here is to share the advances in a research programme which intention is to provide tools and resources to help improve team performance in the development of innovation projects.

The model proposed, and the corresponding tool, had been the result of a creative combination of theoretical, practical and applied perspectives. From this point, with a consistent model, it will be possible to continue with the development of new functionalities oriented to make recommendations to individuals and teams about strategies to improve their management.

\section{REFERENCES}

[1] G. Akehurst, J.M. Comeche and M.A. Galindo, "Job satisfaction and commitment in the entrepreneurial SME" Small Business Economic: and entrepreneurship journal. Vol. 32(3) pp 299-289, 2009.

[2] IBM Institute for Business Value (2010), “The IBM Global CEO Study 2010",(Accesed 31-08-2013) availaible in : http://www05.ibm.com/services/es/ceo/ceostudy2010/index.html

[3] C.M. Ford, "A theory of individual creative action in multiple social domains” Academy of Management Review. Vol. 21(4) pp. 1112-1142, 1996.

[4] E. Junarsin, “Managing discontinuos innovation” Int. Manage Rev. Vol. 5 pp. $10-18,2009$.

[5] T. Kelly and J. Limman, The ten faces of innovation: Strategies for heightening creativity, Profile Book LTD: United Kingdom 2009.

[6] E. de Bono, Six Thinking Hats: An Essential Approach to Business Management, Little, Brown and Company: 1985

[7] E. Mannix and M. Lean, "Diverse Teams in Organizations" Psychological Science in the Public Interest. Vol. 6(2)

[8] D. Mascia, J. Björk and M. Magnusson, "Background” Organizing Ideation, Creativity and Innovation: The Role of Social Networks. Creativity and Innovation Management. Vol. 21 pp. 458-459, 2012.

[9] M. Pallot (2009), ECOSPACE Survey on Barriers Affecting Collaboration Effectiveness and Efficiency; ECOSPACE Newsletter, (Accesed 31-08-2013) availaible in : http://www.amicommunities.eu/wiki/ECOSPACE_Newsletter_No_11\#ECOSPACE_Su rvey_on_Barriers_Affecting_Collaboration_Effectiveness_and_Efficien cy

[10] A.Pirola-Merlo and L. Mann, "The relationship between individual creativity and team creativity” Journal of Organizational Behaviour. vol. 25 pp. 235-257, 2004.

[11] S. Seidel, F. M. Muller-Wienbergen and M. Rosemann, "Pockets of creativity in business processes" Communications of the Association of Information Systems. Vol. 27(1) pp. 415-436.

[12] F. Trompenaars and C. Hampden-Casares, Innovating in a global crisis,. Infinite Ideas Limited: 2009.

[13] M. A. West, "Sparkling Fountains or Stagnant Ponds: An Integrative Model of Creativity and Innovation Implementation in Work Groups" Applied Psychology: An International Review. vol. 51(3) pp. 355-424, 2002

[14] M.A. West and J.L. Farr , "Innovation at work: Psychological and organizational strategies”, in M. A. West, \& J. L. Farr (Eds.), Innovation and creativity, pp. 3-14, 1990, Chichester: Wiley. 